\title{
LA ACTUAL REGULACION DE LA CONTRATACION LOCAL
}

352.712

por

\author{
Jaime Sánchez Isac
}

Secretario de primera categoria de Administración Local

SUMARIO: I. INTRODUCCION.-II. LOS LIMITES DE LA ACTIVIDAD CONTRACTUAL.-III. LA PRELACION DE NORMAS EN LOS CONTRATOS DE LAS ENTIDADES LOCALES. - IV. LA APLICACION SUPLETORIA DE LA LEGISLACION SOBRE CONTRATOS DEL ESTADO.-V. POTESTADES ADMINISTRATIVAS EN LA CONTRATACION: 1. INTERPRETACIÓN DE LOS CONTRATOS. 2. AUDIENCIA DEL CONTRATISTA. RESPONSABILIDADES E INDEMNIZACIONES. - VI. EXPEDIENTES DE CONTRATACION.-VII. FORMAS DE ADJUDICACION.VIII. EL PROBLEMA DEL LLAMADO "CONTRATO DE GESTION DE SERVICIOS PUBLICOS». - IX. LOS SISTEMAS DE SELECCION DE CONTRATISTAS: 1. CoNCURSO. 2.. ConTRATACION DIRECTA.$X$. DOCUMENTACION DE LOS CONTRATOS.-XI. CONCLUSIONES.

\section{INTRODUCCION}

Una especial preocupación por la contratación local y muchos años de práctica secretarial nos han movido a resumir algunas sencillas observaciones sobre el tema, desde la Secretaría y pensando en tantos compañeros que, estos últimos meses, se han encontrado ante la misma problemática concreta.

Es innecesario insistir en que este trabajo no tiene otra pretensión que meditar sobre cuestiones concretas y candentes. Por ello hemos prescindido de todo aparato bibliográfico, dada la índole 
del estudio, absolutamente circunscrito a una glosa de unos preceptos vigentes, que podrían merecer, sin duda, una atención más profunda y ramificada, aunque, tal vez, en su sencillez, tenga valor práctico e inmediato para los funcionarios de los Cuerpos Nacionales que cada día intervienen en la actividad contractual de nuestras Corporaciones por imperativo profesional inexcusable.

\section{LOS LIMITES DE LA ACTIVIDAD CONTRACTUAL}

El Real Decreto 3046/77, de 6 de octubre (Boletin Oficial del Estado núm. 283, de 26-XI-77), plantea una serie de cuestiones que tuvieron ya, algunas de ellas, una primera aproximación en el XXV Seminario de Investigación del Instituto de Estudios de Administración Local, que versó, precisamente, sobre el tema de la aplicación de los principios del Derecho contractual estatal a las Corporaciones locales.

El artículo 108 del Texto articulado parcial de la Ley 41/1975 de Bases del Estatuto de Régimen local, que seguimos, sienta un principio similar al de la autonomía de la voluntad, que es tradicional en nuestro Derecho peninsular para la esfera civil.

Creemos que el citado artículo 108 (1) tiene importancia porque es una base de consideración de la total actividad de las Entidades locales, en cuanto que, en su actuación, deben partir de una idea o concepto de libertad legal, es decir, dentro de la Ley, deben sentirse moralmente capacitadas para hacer todo aquello que la Ley no prohíba, dentro de las genéricas limitaciones del artículo 108.

El artículo 108 del Texto articulado es una llamada a la imaginación de nuestros políticos y de nuestros funcionarios para que, honestamente, traten y convengan aquello que necesiten para sus Corporaciones locales. Hemos vivido largos decenios de temor al defecto formal, de temor reverencial al trámite. Todo esto ha sido superado, en gran medida en base del espiritualismo de nuestro Tribunal Supremo. Debe superarse todavía más. Debe llegar la hora de libertad y desentumecimiento para la Administración. Las consecuencias prácticas de esta actitud son imprevisibles, ya que, en

(1) «Las Entidades locales podrán concertar los contratos, pactos o condiciones que tengan por conveniente, siempre que no sean contrarios al interés público, al ordenamiento jurídico o a los principios de buena administración, y deberán cumplirlos a tenor de los mismos, sin perjuicio de las prerrogativas establecidas, en su caso, en favor de dichas Entidades». 
realidad, lo que está en juego es el aire, el estilo, el corte del hacer administrativo.

Los tres conceptos jurídicos indeterminados, verdadera trinidad de la Administración, el interés público, el ordenamiento jurídico y los principios de buena administración, son un marco amplio, de una complejidad dogmática y de una trascendencia ideológica que conectan nuestra materia contractual con los más firmes y progresivos avances de nuestro sistema jurídico-administrativo.

La primera llamada de atención que debemos hacer ante el nuevo régimen de contratación local es, precisamente, su actualidad, su sentido del presente social, su conciencia del grave bache existente entre nuestras normas locales y las necesidades que las Corporaciones locales han de satisfacer.

\section{LA PRELACION DE NORMAS EN LOS CONTRATOS DE LAS ENTIDADES LOCALES}

En el artículo 109 del Texto refundido encontramos una triple división de los contratos que es paralela a la que podemos estudiar en el artículo $4 .^{\circ}$ de la Ley de Contratos del Estado, Texto articulado aprobado por Decreto 923/1965, de 8 de abril, modificada parcialmente por Ley 5/1973, de 17 de marzo.

Existen, pues, tres grandes clasificaciones de los contratos:

a) Contratos nominados: ejecución de obras, gestión de servicios públicos y prestación de suministros.

b) Contratos innominados: préstamo, depósito, transporte, arrendamiento y cualesquiera otros que tengan carácter administrativo.

c) Contratos no administrativos de la Administración.

La prelación de normas aplicable a cada clase viene indicada en el propio artículo 109. A efectos prácticos, el supuesto más importante es el de los contratos administrativos nominados que se regirán, en primer lugar, por las normas del Texto articulado, sus disposiciones reglamentarias, en pie de igualdad, y supletoriamente, por la Ley de Contratos del Estado y las restantes normas de Derecho administrativo.

En defecto de este último, serán de aplicación las normas de Derecho privado. 
La primera consecuencia práctica, de real trascendencia, para los funcionarios de Administración local, se halla en estas «disposiciones reglamentarias», que no existen, hasta el momento.

Ciertamente, la disposición transitoria primera (2) y la Tabla de preceptos, de vigencias y derogaciones, nos suministran unas bases de trabajo, para contestarnos una cuestión de derecho intertemporal, que creemos tendrá una duración larga: ¿Cuál es el precepto aplicable a determinado punto de nuestro campo de actividades contractuales?

Existe una inclusión en la Tabla de preceptos de una importancia capital: la derogación de los artículos 307 al 353, ambos inclusive, del Texto articulado y refundido de la Ley de Régimen local, aprobado por Decreto de 24 de junio de 1955. Dichos artículos tratan de las formas de contratación de bienes, obras y servicios.

Del conjunto de preceptos sobre la transitoriedad de nuestro régimen contractual emerge una primera cuestión básica: Es perfectamente posible la superposición -y consiguiente colisión- de los preceptos de los Reglamentos de Contratación y de Servicios (que desarrollan, precisamente, los artículos 307 al 318), con las normas del Texto articulado por Real Decreto 3046/77, de 6 de octubre, y toda la compleja normativa de la Ley y Reglamento de Contratación del Estado, que se introducen en nuestro Régimen local del modo y manera que estudiamos.

En puridad de principios, la Ley de Régimen local, Texto refundido de 24 de junio de 1955, carece de vigencia legal en España, en lo que se refiere a contratos de las Entidades locales (3).

Ello confiere a la materia un radical problematismo y a su estudio una gran actualidad.

En una aproximación práctica al tema, lo innegable, en lo que se refiere a los contratos administrativos nominados, será el manejo inmediato de la Ley y el Reglamento de Contratos del Estado, primera fuente supletoria, su conexión con nuestros Reglamentos de

(2) «Hasta la aprobación de los Reglamentos de ejecución de la presente Ley continuarán vigentes las disposiciones de los Reglamentos de Funcionarios de Administración local de 30 de mayo de 1952, de Contratación de 9 de enero de 1953 y de Servicios de las Corporaciones locales de 17 de junio de 1955, en cuanto no se opongan a esta Ley". Al propio tiempo en la Tabla de preceptos sobre Régimen local que continúan vigentes o quedan derogados, se citan el Decreto de 9 de enero de 1953, «Reglamento de Contratación de las Corporaciones locales. Vigente en cuanto no se oponga al presente Texto articulado».

(3) Es importante subrayar la concepción del contrato como atécnica para la obtención de colaboración de los particulares», como nos recuerda el profesor don Ramón Martí Mateo, Manual de Derecho administrativo, pág. 427. 
Contratación y de Servicios, que están engarzados en una estructura sistemática y cuya vigencia es innegable, de conformidad con las taxativas declaraciones de la disposición transitoria primera.

Sin duda es de urgente necesidad la promulgación de una legislación dotada de plenitud y coherencia que abarque y comprenda toda la materia de la contratación local, lo cual únicamente tendrá lugar cuando las reglamentaciones de ejecución de la Ley tengan existencia autónoma y real.

El modus actuandi seguido en el Real Decreto 3046/77 tiene graves inconvenientes prácticos, ya que si siguiéramos la mecánica de los preceptos positivos, citados, deberíamos recurrir, en este momento, a los textos estatales.

Por todo ello, es de desear una pronta finalización de esta situación de interinidad legislativa, a fin de concretar y definir claramente la materia en un reglamento que posiblemente debería abarcar contratación y servicios, como hizo la Ley refundida derogada y la Ley y el Reglamento de Contratos del Estado. Esta exigencia de unidad de régimen de los contratos administrativos nominados obligará a un planteamiento total de ambas especialidades, contratación y servicios, tan importantes en la praxis de la Vida local.

En definitiva, toda la dificultad de aplicación del Real Decreto $3046 / 77$, de 6 de octubre, reside en la aplicación de la disposición transitoria primera. Desde un punto de vista práctico, por tanto, hasta que se publiquen los reglamentos, deberemos estudiar, en cada situación concreta, qué precepto del Reglamento de Contratación de 9 de enero de 1953 está vigente, yendo, en primer lugar, a los artículos 104 al 124 del Real Decreto, para dilucidar si el extremo concreto que nos cuestionamos se halla incluido en su disciplina.

\section{LA APLICACION SUPLETORIA DE LA LEGISLACION SOBRE CONTRATOS DEL ESTADO}

En el artículo 110 del Real Decreto encontramos, en once apartados, una serie de preceptos sobre cómo se va a utilizar, supletoriamente, la Ley de Contratos del Estado.

La primera conclusión general que puede abstraerse de dicho artículo, ante las reglas 3." (supuestos de incapacidad o incompatibilidad) y $4 .^{a}$ (mesa de contratación), es que deberemos esperar dis- 
posiciones reglamentarias para la aplicación de las mismas, pudiendo, por tanto, entender estas reglas como condicionadas, suspensivamente, para su vigencia, a la promulgación de los correspondientes reglamentos. Esta observación vale, con generalidad, para cualquier otro artículo del Real Decreto que se remita a otra norma que lo ha de desarrollar.

En conjunto, el artículo 110 tiene un carácter instrumental, ya que, teóricamente, nos sirve para suplir las lagunas y deficiencias conceptuales de la Ley y el Reglamento de Contratos del Estado, disposiciones supletorias en primer grado, para los contratos nominados.

Dicho artículo, no obstante, nos plantea dudas interpretativas en puntos tan importantes como la competencia (4) en la contratación, regulada en la norma 2.a.

Hasta ahora, la materia se concretaba así:

El artículo 122 del Reglamento de Organización, Funcionamiento y Régimen jurídico de las Corporaciones locales sienta la regla general, hasta el momento, defiriendo al Ayuntamiento Pleno la competencia de: "1. Aprobar los pliegos de condiciones facultativas, económicas y administrativas que hayan de servir de base a la contratación y concesión de obras y servicios, salvo cuando correspondan a la competencia de la Comisión Permanente».

El artículo 123 del propio Reglamento, en su punto $2 .^{\circ}$, complementa al anterior, asignando a la Comisión Permanente: «2. La contratación y concesión de obras y servicios cuya duración no exceda de un año o que no exijan créditos superiores a los consignados en el presupuesto ordinario, previa formación de expediente en el que figuren los informes técnicos imprescindibles para acreditar de modo terminante aquellas circunstancias, sin las cuales los indicados actos corresponderán al Ayuntamiento Plenon.

En cuanto a la ordenación del gasto, el artículo 707 de la Ley de Régimen local la tribuye, en su apartado a), "al Presidente de la Corporación, cuando se trate de gastos fijos y de atenciones ordinarias, dentro de los límites fijados por la Corporación», y b), "al órgano corporativo de cada Entidad local, en los demás casos».

Esta sistemática municipal tiene la coherencia y la funcionali-

(4) «2.: En todo caso, el acuerdo aprobatorio del expediente de contratación y de apertura de procedimiento de adjudicación corresponderá al órgano que sea competente conforme a la Ley para ordenar el gasto. Comprenderá la aprobación del pliego de cláusulas económico-administrativas e irá precedida de los informes del Secretario y del Interventor de la Corporación». 
dad de la organización de las Entidades locales, caracterizada, en líneas generales, por su connatural descentralización presupuestaria, que deriva de la multiplicidad de Corporaciones que integran la totalidad de la Administración local.

La problemática en el Estado es completamente distinta, por la división ministerial y el papel central que el Ministerio de Hacienda tiene en la disposición y el control de los fondos que se utilizan en la contratación del propio Estado.

Ello queda bien patente en múltiples puntos del articulado del Reglamento de Contratos del Estado, aprobado por Decreto de 25 de noviembre de 1975, número 3410/75 (5).

Es claro que, de conformidad con los artículos 122, 123 del Reglamento de Organización, Funcionamiento y Régimen jurídico y 707 de la Ley de Régimen local, la dotación del gasto queda bien diferenciada de las competencias contractuales, que aquí están mucho más unidas e imbricadas.

Recordemos el artículo 119 del Real Decreto 3046/77 (6), que es la transcripción del artículo 24 del Reglamento de Contratación. En el régimen actual todos los pliegos de condiciones deberian aprobarse en sesión plenaria, lo cual no quedaba tan estrictamente fijado en el sistema anterior, ya que el artículo 2 del Reglamento de Contratación admite la pluralidad de competencias para contratar, atribuidas «a los distintos órganos municipales y provinciales», y la misma norma les asigna las facultades de «aprobar y modificar los pliegos de condiciones".

En este momento, por tanto, sólo puede afírmarse, sobre la competencia contractual, en conclusión:

1. Existe una antinomia entre el artículo 110.1 y 2 del Real Decreto $3046 / 77$.

(5) Véase, por ejemplo, el artículo 83: «Realizado el replanteo de la obra, se iniciará el expediente por acuerdo del órgano de contratación, debiendo incorporarse al mismo, en todo caso, el pliego de cláusulas administrativas particulares que haya de regir en el contrato, el certificado de existencia de crédito y los informes de la Asesoría Jurídica y de la Intervención del Estado». En correlación, el artículo 19: aLos jefes de los Departamentos ministeriales son los organos de contratación del Estado y están facultados para celebrar en su nombre los contratos a que se refiere el presente capítulo, dentro del ámbito de su competencia, previa consignación presupuestaria para este fin y con sujeción a los requisitos establecidos en la Ley de Contratos del Estado y su Reglamento generaln.

(6) a1. Los pliegos de condiciones, después de aprobados por el Pleno de la Corporación, se expondrán al público durante el plazo de ocho días, anunciándose así en el Boletín Oficial de la Provincia, para que puedan presentarse reclamaciones, las cuales serán resueltas por la misma Corporación. 
2. Se conectan la competencia de contratación y la ordenación del gasto, que en nuestro Derecho positivo local, hasta ahora, se hallaban claramente separadas y cuya articulación tiene su base en la organización general de los Entes locales.

Las reglas del artículo 110 , por otra parte, son claras y obvias. Todas ellas tienden a «traducir» la estructura general del Estado a la local.

Así, podemos destacar:

- La Asesoría Jurídica es la Secretaría de la Corporación (regla $\left.5 .^{\mathrm{a}}\right)$.

- La fiscalización corresponde al Interventor de la Entidad (regla 6. ${ }^{\mathrm{a}}$ ).

- La fe pública administrativa es competencia del Secretario (regla 7.a).

- La fianza puede depositarse, indistintamente, en la Caja General de Depósitos o en la de la Corporación contratante (regla $8 .^{\mathrm{a}}$ ).

- Se admite aval bancario (regla 9. ${ }^{\mathrm{a}}$ ).

- No procede el registro de contratistas de las Corporaciones locales en el Ministerio de Hacienda (regla 10. ${ }^{\mathrm{a}}$ ).

- Es potestativa la constitución de Juntas de Compras (regla $\left.11 .^{\mathrm{a}}\right)$.

\section{POTESTADES ADMINISTRATIVAS EN LA CONTRATACION}

El artículo 111 del Real Decreto 3046/77 expone una serie de competencias que llama prerrogativas, que inciden, aunque con extrema concisión expresiva, en preceptos del Reglamento de Contratación.

\section{INTERPRETACIÓN DE LOS CONTRATOS}

Se defiere al órgano competente para contratar. El contenido del artículo 111.1 coincide sustancialmente con los artículos 99 y 100 del Reglamento de 1953. Es destacable la intervención que en el número 3 del propio artículo 111 se establece, en relación al Servicio Nacional de Inspección y Asesoramiento de las Corporaciones 
Locales, sin perjuicio, añade el artículo, «de que el Ministerio, en tal supuesto, cuando la trascendencia del caso lo aconseje, recabe dictamen del Consejo de Estado».

Es realmente insólita, y hasta ahora desconocida, esta intervención por vía de informe, en todo caso potestativo, del Consejo de Estado. Nos hallamos ante un mecanismo de tutela que, en materia contractual, no existía en nuestro ordenamiento local (7).

\section{AUDIENCIA DEL CONTRATISTA. \\ RESPONSABILIDADES E INDEMNIZACIONES}

En el artículo 111.2 se recuerdan ambos principios, sin que ello parezca ser otra cosa que una reiteración de preceptos procesales y sustantivos que debemos calificar de comunes y habituales.

\section{EXPEDIENTES DE CONTRATACION}

En el artículo 112 del Real Decreto 3046/77 encontramos recogida la clasificación de los expedientes de contratación, que exponen los artículos 83 a 91 del Reglamento de Contratos del Estado, en correlación con el artículo 25 de la Ley que desarrolla.

La diferenciación es esencialmente formal, sin otras conscuencias que las que se indican en las citadas normas. Especial interés, no obstante, tiene el procedimiento excepcional para supuestos de emergencia, en cuanto puede ser de real importancia práctica.

El artículo 114 habla de "obras, servicios, adquisiciones o suministros de emergencia, a causa de acontecimientos catastróficos o situaciones que supongan grave peligro o necesidades que afecten directamente a la seguridad pública».

Es evidente que nos encontramos ante unos conceptos jurídicos indeterminados que la Administración local deberá sustanciar y corporeizar en la problemática diaria. Ciertamente, no creemos que este precepto pueda, en puridad de principios, ser de aplicación habitual (ya que no es éste el espíritu de la norma), pero sí puede ser una válvula de seguridad para situaciones extremas, realmente factibles y existentes en la Vida local.

No será por demás aconsejar una extremada prudencia en el

(7) Sin duda nos hallamos ante una regulación que está en función de la revisión de oficio, reconocida en el artículo 42 del Reglamento de Contratos del Estado. 
uso de estas potestades excepcionales en la calificación procedimental de un expediente, ya que su propia naturaleza fáctica exige también una escrupulosa ponderación en la aplicación de la tramitación de emergencia que estudiamos. La primera precaución ante la aplicación pragmática a un supuesto debería tener como norte proveer al acopio de un sustrato de informes técnicos, como garantía de objetividad en la aplicación de un procedimiento excepcional.

Las consecuencias jurídicas del expediente de emergencia son: 1. Basta acuerdo del Ayuntamiento Pleno para contratar libremente, "sin sujetarse a los requisitos formales establecidos en esta Ley". La expresión jurídica - que tiene su antecedente en el artículo 27 de la Ley de Contratos del Estado, si bien se reduce la excepcionalidad a la Defensa Nacional- puede ponerse en contacto con el supuesto de nulidad de pleno derecho previsto en el artículo 47.1.c de la Ley de Procedimiento administrativo (8).

Del paralelismo de preceptos se concluye que nos hallamos ante una habilitación legal para un supuesto que nos abocaría a una nulidad de pleno derecho en la actuación corporativa, sin tal previsión legal.

En un plano práctico interpretamos el artículo 114.1 del Real Decreto en el sentido de que basta un simple acuerdo municipal plenario para la libre contratación de obras, servicios y suministros.

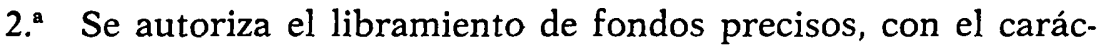
ter de "a justificar", sin perjuicio de instruir el oportuno expediente de modificación de crédito, cuando fuere necesario.

Es importante recordar que el artículo 41 del Reglamento de Contratos del Estado prevé la nulidad de pleno derecho de los actos administrativos preparatorios o del acto de adjudicación para el caso de «las adjudicaciones de contratos que carezcan de consignación presupuestaria debidamente aprobada».

En la misma línea, con carácter general, el artículo 709 de la Ley de Régimen local establece un supuesto de nulidad absoluta por la misma razón (9).

(8) Los dictados prescindiendo total y absolutamente del procedimiento legalmente establecido para ello o de las normas que contienen las reglas esenciales para la formación de la voluntad de los organos colegiados».

(9) Art. 709. «1. Serán nulos los acuerdos de las Corporaciones y resoluciones de autoridades municipales y provinciales: $a$ ) Que habiliten gastos que no tengan crédito suficiente para satisfacerlos, y $b$ ) Que creen nuevos servicios, sin previa dotación o den mayor extensión a los establecidos, rebasando el crédito correspondiente. 2. Los Interventores, en estos casos, harán constar por escrito la advertencia de nulidadn. 
Del contenido del artículo 114.1 se deduce la evidente posibilidad de adoptar acuerdos que estén exentos de la taxativa prohibición del artículo 709, que prevé una concreta advertencia de nulidad para el Interventor de Fondos. Como siempre, la corrección del procedimiento excepcional residirá en la motivación real del acto, que debe responder a la teleología del precepto, vinculado a un elemento de la vida jurídica tan esencial y al propio tiempo tan delicuescente como la «seguridad pública».

Esta vía de excepcionalidad viene confirmada por el segundo párrafo del artículo 114, que establece, con generalidad, la vigencia de las normas contractuales ordinarias para los demás supuestos (10).

\section{FORMAS DE ADJUDICACION}

El artículo 115, párrafo $1 .^{\circ}$, no introduce cambio fundamental en el sistema del Reglamento de Contratación de 1953. Se siguen manteniendo la subasta, el concurso-subasta, el concurso y la contratación directa. Tal vez sea destacable la evidente mejora de técnica expresiva consistente en sustituir el título "Formas de contratación" por el de "Formas de adjudicación", en cuanto, obviamente, si bien el acto adjudicatorio constituye el perfeccionamiento del contrato no es el contrato en sí. La real importancia del precepto, que innova radicalmente la materia, reside en el párrafo dos del propio artículo 115 (11).

La Corporación puede optar entre la subasta y el concurso-subasta sólo si se trata de "proyectos de obra muy definidos y de ejecución sencilla». La visión del artículo 12 del Reglamento de 1953 era diametralmente opuesta (12), en cuanto la exigencia de la su-

(10) $\alpha$. El resto de las obras, servicios, suministros o adquisiciones que puedan ser necesarios, se contratarán de conformidad con lo establecido en estas normas》.

(11) «Cuando se trata de obras, la Entidad local podrá optar entre la subasta y el concurso-subasta como forma de adjudicación, si se trata de proyectos de obras muy definidos y de ejecución sencilla, cuya cuantía sea inferior a 25 millones de pesetas. Si los proyectos de obras no reúnen los expresados requisitos o su presupuesto fuere de cuantía superior a la indicada, procederá, con carácter general, el concurso-subasta".

(12) $\alpha 1$. Los contratos en que intervengan las Corporaciones locales se celebrarán, por regla general, mediante subasta pública, cualquiera que sea la naturaleza origen o destino de los fondos que se hayan de abonar o percibirn. El artículo 307 de la Ley de Régimen local, asimismo derogado por el Real Decreto 3.046 de 1977, tenía texto totalmente coherente con el precepto reglamentario citado: «1. Los contratos que celebran las Entidades locales se realizarán, por regla general, mediante subastan. 
basta era general y conminatoria. Cualquier excepción era vista con extrema desconfianza y se exigían unos requisitos formales concretos, como el «quorum» del derogado artículo 311 de la Ley de Régimen local.

Para los contratos superiores a veinticinco millones de pesetas, por tanto, se exige, "con carácter general», el concurso-subasta. Esta forma de selección de contratistas está regulada por los artículos 110 al 112 del Reglamento de Contratos del Estado.

El problema que se nos plantea es muy simple: El artículo 115.2 establece un régimen de aplicación inmediata, es decir, no existe ninguna reglamentación "puente» que nos permita dudar de su inmediata aplicación (artículo 109.1. $)$.

Ahora bien, en el "concurso-subasta" que hemos de aplicar, ¿deberemos publicar el resultado de la primera fase del procedimiento, esto es, el concurso, en el Boletín Oficial de la Provincia, señalando la fecha de apertura de los segundos pliegos, como establece el artículo 39.3. ${ }^{a}$ del Reglamento de Contratación de 1953?

Si la contestación fuera afirmativa, no advertimos qué ventaja fundamental puede existir en el nuevo régimen, a no ser la generalidad y homologación del concurso-subasta con la subasta y poder, con la ley en la mano, soslayar el automatismo de la adjudicación, cuyos inconvenientes conocemos sobradamente los Secretarios de Administración local.

¿No sería más lógico reconocer que el "concurso-subasta» del artículo 115.2 es el desarrollado por los artículos 110 a 112 del Reglamento de Contratos del Estado?

Al suprimir la publicación intermedia obtenemos la primaria ventaja de la economía procesal en la selección discrecional de los proponentes. Conocemos casos en que se ha aplicado directamente la forma del concurso-subasta estatal con perfecto éxito y corrección temporal.

\section{EL PROBLEMA DEL LLAMADO «CONTRATO DE GESTION DE SERVICIOS PUBLICOS»}

Hasta ahora no había aparecido en nuestro Derecho local esta forma contractual, que el profesor GARCíA DE ENTERRfa critica duramente (13), en cuanto «más que un tipo contractual definido es una

(13) Curso de Derecho administrativo, I, Madrid, 1974, pág. 533. 
simple técnica de gestión de los servicios públicos, la llamada indirecta o por medio de empresas, por oposición a la gestión directa o realizada por los propios medios administrativos, incluyendo entre éstos los entes instrumentales».

"Una vez más, resulta más correcta la normativa local. El Reglamento de Servicios de las Corporaciones locales, de 1955, regula esta materia en su título II, distinguiendo la gestión directa (artículo 41), mixta (artículo 102) e indirecta (artículo 113) de los servicios locales; sólo ya dentro de este último tipifica tres formas contractuales que en modo alguno pretende unificar, como intenta la Ley de Contratos del Estado, en el lecho de Procusto de un supuesto contractual único». Parece que la claridad de la cita -anterior, como es lógico, al Real Decreto 3046/77-, puede ser argumento para ser extremadamente cautos al enfrentarnos ante esta nueva figura, en nuestro Derecho local práctico. El carácter esencial, casi diríamos esquemático, del Real Decreto 3046, que le da carta de naturaleza en nuestra Administración local, la propia naturaleza transitoria de nuestro régimen privativo, la necesaria definición de tantos aspectos que, hoy por hoy, están simplemente esbozados en esta disposición, nos exigen una gran precaución ante la aplicación del artículo 115.3 (14).

\section{LOS SISTEMAS DE SELECCION DE CONTRATISTAS}

\section{Concurso}

El artículo 116 es una transcripción del artículo 35 de la Ley de Contratos del Estado, con la innovación de la introducción del "concurso restringido", que se regulará por lo previsto para el trámite de la admisión previa de licitadores en el concurso-subasta, previsión que abunda en la postura de que esta última figura, en nuestro sistema actual, es la prevista en la legislación estatal.

El artículo 37 del Reglamento de Contratación de 1953 tenía algún supuesto de especial utilidad práctica que, ahora, se ha suprimido, como el número.3 (15), cuya virtualidad y capacidad de adap-

(14) aLos contratos de gestión de servicios públicos y los de adquisiciones o suministros se adjudicarán ordinariamente mediante el procedimiento de concurson.

(15) «Podrán celebrarse por concurso-subasta o por concurso los contratos siguientes: ... 3..$^{\circ}$ Los que por su naturaleza especial exijan garantías o condiciones también especiales por parte de los contratistas». 
tación a muchos casos de nuestra Vida local nos son bien conocidos. Debería, por tanto, hallarse algún camino sistemático en la nueva regulación que permitiera subsistir tal precepto o alguno paralelo.

\section{CONTRATACIÓN DiRECTA}

Los artículos 117 y 118 del Real Decreto 3046/77 están dedicados a la contratación directa. Si cotejamos tales preceptos con el artículo 41 del Reglamento de Contratación, concluimos:

a) La desaparición del apartado $1 .^{\circ}$ (16) del artículo 41 del Reglamento de Contratación.

b) La supervivencia del contenido de los números 2 y 3 del artículo 41 en el artículo $117.1 .1 .^{\circ}, 2^{\circ}$ y $3 .^{\circ}$ del Real Decreto 3046/77.

La "reconocida urgencia», el más socorrido título de nuestras excepciones prácticas de subasta, se vincula aquí a que sea "surgida como consecuencia de necesidades apremiantes que demandaran una pronta ejecución", substrato fáctico de una cierta generosidad.

c) Continúa la referencia a unos límites mínimos reglamentarios, aunque se determina ya "sin que en ningún caso puedan ser superiores a cinco millones de pesetas o, si se trata de gestión de servicios, que su plazo de duración no sea superior a dos años».

Es importante recordar el Real Decreto 1201/78, de junio 1978 (Boletín Oficial del Estado de 7 de junio), donde con apoyatura en el artículo 117, apartado cuarto, del Real Decreto 3046/77, se llena el vacío reglamentario, que se acusa, determinando un doble límite, la cantidad de cinco millones y el 5 por 100 del presupuesto ordinario de ingresos de cada Corporación, para la regulación del concierto directo.

Es muy importante el artículo segundo del propio Real Decreto $1201 / 78$ (17), en cuanto nos plantea dudas sobre la vigencia de los restantes apartados del artículo 41 del Reglamento de Contratación, ya que no son derogados, y nos encara frente a otra cuestión de mayor envergadura: la real dimensión de la disposición transi-

(16) «Los que se refieren a operaciones de Deuda, negociación de efectos públicos o transporte material de fondos».

(17) "Queda derogado el número 6 del artículo 41 del Reglamento de Contratación de las Corporaciones locales, de 9 de enero de 1953». 
toria primera del Real Decreto 3046/77, que hemos esbozado anteriormente.

d) Se introduce un nuevo supuesto de urgencia, el «notorio carácter artístico con arreglo al dictamen de organismos competentes".

e) Se modifica el contenido del artículo 41, apartados 5 y 6 del Reglamento de Contratación, explicitándose el procedimiento de no adjudicación y suprimiendo la casuística, previa al concierto directo, de segunda subasta o un concurso desiertos.

f) Se introduce, para todos los casos en que es posible la concurrencia, la consulta con tres empresas (artículo 117.2).

g) Existe una remisión a la Ley de Contratos del Estado, en cuanto a ejecución directa por administración de obras, "sin perjuicio de las limitaciones que reglamentariamente se establezcan", esto es, con otra previsión de futura legislación sobre este punto concreto (artículo 118).

\section{DOCUMENTACION DE LOS CONTRATOS}

El artículo 110.7 es de una cierta vaguedad de expresión, susceptible de crear confusiones, en un campo tradicionalmente reclamado por el Secretariado de Administración local, esto es, el ejercico de la fe pública en materia contractual, sin limitaciones (18).

$¿$ Hemos de interpretar la disyuntiva defiriendo a la voluntad corporativa, potestativamente, el uso del documento notarial o del administrativo?

Creemos que esta interpretación no es válida, ya que, por una parte, los artículos 48 a 50 del Reglamento de Contratación no tienen, en su contenido, esta generosidad del Real Decreto, que creemos aparente, y, por otra, el artículo 40 de la Ley de Contratos del Estado especifica ya, a nivel legal, los casos en que procede la escritura pública notarial para los contratos de obra.

La postura más prudente será, por tanto, continuar con el régimen del Reglamento de Contratación, por razones de duda razonable sobre la vigencia inmediata del artículo 110.7. ${ }^{\mathrm{a}}$, ya que no se ha promulgado ninguna derogación explícita de los artículos corre-

(18) «El contrato se formalizará en escritura pública o en documento administrativo, dando fe en este caso el Secretario de la Corporación.. 
lativos del Reglamento de Contratación y cabe esperar el detalle reglamentario preciso, juntamente con el resto de aspectos que han quedado diferidos a lo que en el futuro se establezca.

\section{CONCLUSIONES}

El sistema de contratación local tiene planteada, con carácter de urgencia, la necesidad de una reestructuración total.

La tendencia a la uniformidad, en el tratamiento de la materia, unificando, en lo posible, los contratos del Estado y los de la Administración local, no ha de ser obstáculo para que se vaya a la promulgación de un Reglamento completo, que evite las constantes referencias a la supletoriedad y la utilización indiscriminada de preceptos estatales.

Las especiales condiciones de la Administración local exigen una regulación adaptada a las mismas, lo suficientemente detallista como para ser aplicada sin problemas de interpretación o articulación de normativas distintas.

En este momento histórico, en que la renovación legislativa viene impuesta por el desarrollo de la Constitución de 1978 y por razones sociopolíticas, nos hallamos ante la coyuntura precisa para que esta disciplina, global y meditada, pueda realizarse de modo óptimo. La oportunidad y la necesidad de la misma creemos que son claras, a la vista de la importancia cotidiana de la contratación en la vida de nuestras Corporaciones locales. 